\title{
Nutrient intake variability and number of days needed to assess intake in preschool children
}

\author{
Maijaliisa Erkkola ${ }^{1 *}$, Pipsa Kyttälä ${ }^{2,3}$, Hanna-Mari Takkinen ${ }^{3}$, Carina Kronberg-Kippilä², \\ Jaakko Nevalainen $^{3,4}$, Olli Simell ${ }^{5}$, Jorma Ilonen ${ }^{6}$, Riitta Veijola ${ }^{7}$, Mikael Knip ${ }^{8,9}$ and Suvi M. Virtanen ${ }^{2,3,9}$ \\ ${ }^{1}$ Division of Nutrition, Department of Food and Environmental Sciences, PO Box 66, FI-O0014, University of Helsinki, \\ Helsinki, Finland \\ ${ }^{2}$ Unit of Nutrition, Department of Lifestyle and Participation, National Institute for Health and Welfare, PO Box 30 , FI-O0271 \\ Helsinki, Finland \\ ${ }^{3}$ Tampere School of Public Health, FI-33014, University of Tampere, Tampere, Finland \\ ${ }^{4}$ Statistics Unit, Department of Social Sciences, FI-20014, University of Turku, Turku, Finland \\ ${ }^{5}$ Department of Pediatrics, University of Turku, Kinanmyllynkatu 4-8, FI-20520 Turku, Finland \\ ${ }^{6}$ Immunogenetics Laboratory, FI-20014, University of Turku, Turku, Finland \\ ${ }^{7}$ Department of Pediatrics, PO Box 5000, FI-90014, University of Oulu, Oulu, Finland \\ ${ }^{8}$ Hospital for Children and Adolescents, PO Box 281, FI-OOO29-HUS, Helsinki, Finland \\ ${ }^{9}$ Paediatric Research Centre and Research Unit, Tampere University Hospital and FI-33014, University of Tampere, Tampere, \\ Finland
}

(Received 14 April 2010 - Revised 9 November 2010 - Accepted 12 November 2010 - First published online 12 May 2011)

\begin{abstract}
The duration of the period of time during which diet should be recorded for sufficiently accurate results on the usual intake of an individual is an especially challenging issue in prospective studies among children. We set out to describe nutrient intake variability in preschoolers and to determine the number of record days required $(D)$ to estimate intake of energy and thirty-two nutrients. The diet and the use of dietary supplements were assessed with three consecutive daily food records including one weekend day in 1639 children participating in the population-based birth cohort of the Type 1 Diabetes Prediction and Prevention Project (DIPP) in Finland. Variance ratios and $D$ stratified by sex and age groups were calculated for 455 (1-year-old), 471 (3-year-old) and 713 (6-year-old) children (born between 1998 and 2003). Within:between variance ratios and $D$ increase with increasing age, and are slightly higher for girls. Vitamin A, cholesterol, $n-3$ and $n-6$ fatty acids, $\beta$-carotene and folate intakes require the most replicates. Including supplemental intake has an impact on the variance estimates according to the proportion of supplement users. In the DIPP Nutrition Study with $3 \mathrm{~d}$ food records, the correlation coefficients between observed and true intakes of energy and thirty-two nutrients averaged 0.91 in 1-year-old children, 0.79 in 3-year-old children and 0.74 in 6-year-old children. For providing accurate nutrient intake estimates, three replicates of food records are reasonable in 1-year-old children but must be questioned for several nutrients in 3- and 6-year-old children. The accuracy of ranking boys is greater than that for girls.
\end{abstract}

Key words: Children: Nutrient intake: Variation: Diet records

Increasing evidence points to early dietary intake as a potential risk factor for numerous chronic diseases ${ }^{(1,2)}$. In epidemiological studies, it is essential to know the length of time diet that should be recorded to obtain results that are sufficiently accurate to assess the usual intake of an individual and to rank individuals within the group ${ }^{(3)}$. This is especially challenging in prospective studies among children whose dietary day-to-day variability changes with age ${ }^{(4,5)}$. The number of days needed to measure nutrient intake in groups of individuals is a function of the ratio of the variation within individuals to the variation between individuals ${ }^{(6)}$. The smaller the ratio, the fewer the number of days needed for recording. The optimal number of replicates depends on both the degree of accuracy that is needed and the variability of the nutrient in question $^{(3)}$. For reasons of cost and respondent burden, it is only practical to employ short-term, less ideal methods to

Abbreviations: $S_{\mathrm{w}}^{2}$, within-subject variance; $S_{\mathrm{b}}^{2}$, between-subject variance; DIPP, Type 1 Diabetes Prediction and Prevention

*Corresponding author: Professor M. Erkkola, fax +3589 191 58269, email maijaliisa.erkkola@gmail.com 
estimate usual dietary intake. The consequence of using short-term methods on the distribution of dietary intakes is misleading distributions with artificially increased standard deviations $^{(7,8)}$. Furthermore, measurements of association in epidemiological studies are substantially weakened, possibly to the point of being undetectable.

Studies on nutrient intake variability of preschool children are scarce and mainly published over a decade ago ${ }^{(4-6,9-11)}$. Maximal insight into the relationship between nutrient intake and disease risk requires examining the intakes from both foods and supplements. In the earlier studies, nutrient intake from dietary supplements was not taken into account. The age ranges of the subjects spanned several years. In children, rapid change in variation with age was demonstrated, and, therefore, studies focusing on separate age groups are preferred.

The Type 1 Diabetes Prediction and Prevention (DIPP) nutrition study is a prospective population-based birth cohort study that examines the relationship of maternal diet during pregnancy and lactation, and the child's diet during infancy and early childhood to the development of type 1 diabetes, allergic diseases and asthma in childhood (www. research.utu.fi/dipp/index.php). The diet of the children and the use of dietary supplements are followed up by $3 \mathrm{~d}$ food records and age-specific questionnaires at various ages. We set out to describe nutrient intake variability in children at the ages of 1,3 and 6 years, and to determine the number of daily food records required to estimate intake of energy and thirty-two dietary factors. Accordingly, the correlation coefficients between observed and true intakes of energy and dietary factors based on $3 \mathrm{~d}$ food records were calculated.

\section{Subjects and methods}

We analysed data for 1639 subjects participating in the Finnish DIPP nutrition study ${ }^{(12)}$. The DIPP nutrition study falls within the framework of the larger DIPP study ${ }^{(13)}$. The DIPP study started in 1994, and is an ongoing population-based prospective cohort study aimed at exploring possible means to prevent progression to clinical type 1 diabetes. All newborn infants with human leukocyte antigen-conferred susceptibility to type 1 diabetes were recruited from the university hospital areas of Turku, Oulu and Tampere. The DIPP nutrition study started in Oulu (Northern Finland) and Tampere (Southern Finland) in September 1996 and October 1997, respectively. The study aims at examining the effect of maternal diet during pregnancy and lactation in line with the child's diet during infancy and childhood on the development of type 1 diabetes, allergic diseases and asthma in children. The present study was conducted according to the guidelines laid down in the Declaration of Helsinki, and all procedures involving human subjects were approved by the Ethical Committees of the University of Oulu and Tampere, Finland. Written informed consent was obtained from all subjects. Background information was obtained from a questionnaire completed at 3 months after delivery.

\section{Dietary data}

Data on the child's food consumption were obtained by a $3 \mathrm{~d}$ food record completed close to the child's first, third or sixth birthday. The $3 \mathrm{~d}$ food record comprised two consecutive weekdays and one weekend day. A separate food record was given to day-care personnel if the child was cared for outside the home during the recording days. Families and day-care personnel were instructed to record all the foods and drinks that children had consumed during the recording days with amount, brand, recipe and preparation method. Portion size was estimated either with household measures (e.g. spoons, cups, glasses and decilitres) or using a picture booklet of food portions ${ }^{(14)}$. Vitamin and mineral supplements were recorded by their brand names, and the amounts used were entered as tablets, drops, spoonfuls or millilitres. Trained study nurses checked food records during the respective visits.

Food records were entered and processed with the software Program that uses the Fineli Nutrition Database and the Fineli Dietary Database. Fineli was developed, and is being continuously updated, by the Finnish National Institute for Health and Welfare ${ }^{(15)}$. The dietary database includes 3129 food items and dishes. The DIPP nutrition study added industrial baby foods and infant formulas to the existing food selection of the Fineli Nutrition Database. Additional supplements were entered to the Fineli Nutrition Database in order to improve the selection of supplements used by children. The analytical nutrient values in the database are mostly based on the Finnish studies. In addition, complementary data are obtained from the Finnish food industry and international food composition tables. The system is able to accommodate the creation or modification of specific recipes, and personal recipes were used whenever possible. For food consumption and nutrient intake, an estimate of average daily intake was calculated. Breast-fed children were excluded from the group of 1-yearold children.

\section{Data analysis}

Variance ratios were calculated for nutrient intakes derived from food and, accordingly for selected nutrients, for summed nutrient intakes from food and dietary supplements. A linear mixed model was used to estimate within-subject variance $\left(S_{\mathrm{w}}^{2}\right)$ and between-subject variance $\left(S_{\mathrm{b}}^{2}\right)$, stratified by sex and age groups. Ratios of within- and between-subject variance are expressed as $S_{\mathrm{w}}^{2}: S_{\mathrm{b}}^{2}$. The estimates of the number of days $(D)$ of food records needed to correctly classify individuals depend on the distributions of intake not differing substantially from the normal distribution ${ }^{(10)}$. We tested the normality of the distribution of average individual nutrient intakes with the Kolmogorov-Smirnov one-sample test in every sex and age group. Log transformation was used for nutrients that deviated significantly from normal $(P<0.05)$. However, both untransformed and log-transformed data were calculated for all nutrients in order to evaluate the effect of $\log$ transformations. The formula $\log (x+0 \cdot 01)$ was used for a few zeros in the data. We studied variation in 
altogether fifty-four nutrients (including specific fatty acids) of which thirty-two nutrients are presented here. For some nutrients, log transformation reduced the degree of non-normality but not to the level of being statistically not different from normal in every age and sex group $(P<0 \cdot 05)$. A visual inspection was used, and the estimates of $D$ and correlation coefficient $(r)$ are still presented (the nutrients in question are marked separately in the tables). For the nutrients with a non-normally distributed intake, log-transformed data were used for calculations of $D$ and $r$. Variances and variance ratios are presented for untransformed data.

Calculation of the number of days needed to correctly classify individuals is based on a hypothetical $r$ between observed and actual intakes. The number of days $(D)$ of food records needed to obtain the required $r$ of 0.9 and 0.8 between observed- and true-nutrient intakes was calculated using the following formula that has been applied previously in studies among children ${ }^{(4-6,10)}$ :

$$
D=\frac{r^{2}}{1-r^{2}} \times \frac{S_{\mathrm{w}}^{2}}{S_{\mathrm{b}}^{2}},
$$

where $r$ is the unobservable (hypothetical) correlation between the observed and true mean nutrient intakes of individuals over the period of observation, and $S_{\mathrm{w}}^{2}$ and $S_{\mathrm{b}}^{2}$ are the observed within- and between-subject variances. The estimate of $D$ was rounded down when the additional time was very marginally above the lower number $(<0.05)$. It should be kept in mind that the precision of the estimate of $D$ will decrease with an increasing value of $D$. The following formula, derived from the formula above, was used to determine the level of accuracy achieved in the DIPP study with $3 \mathrm{~d}$ of recording:

$$
r=\left(\frac{D}{D+S_{\mathrm{w}}^{2} / S_{\mathrm{b}}^{2}}\right)^{1 / 2},
$$

where $D$ is the number of days of diet recorded and $S_{\mathrm{w}}^{2}$ and $S_{\mathrm{b}}^{2}$ are as previously defined. The correlation coefficient $r$ is also a measure of the confidence of classification of subjects into their third, fourth, fifth, etc. deciles of the distribution of intakes $^{(10)}$. For $90 \%$ confidence in which $80 \%$ of individuals are classified correctly into thirds of a distribution and $<1 \%$ grossly misclassified, $r$ must be at least $0 \cdot 9^{(6,10)}$. At the $r$ value of $0 \cdot 8,72 \%$ of individuals are classified correctly into thirds of a distribution and $<3.3 \%$ grossly misclassified. Data management was done using SPSS, version 15.0 (SPSS, Inc., Chicago, IL, USA), and data analysis was performed using SAS, version 9.1 (SAS Institute, Cary, NC, USA).

\section{Results}

\section{Characteristics}

The present series comprises 455 (1-year-old) children born in 2003, 471 (3-year-old) children born in 2001 and 713 (6-yearold) subjects born in 1998-9 in the Tampere and Oulu University hospitals for whom food record-based data on food intake were available (Table 1). Of all the children participating in the DIPP nutrition study in those selected years, 71, 57 and $43 \%$ provided 1-, 3- and 6-year food records, respectively. For sixty-two children ( $4 \%$ of all) included in the study, food records were kept for $2 \mathrm{~d}$ and for twenty-three children (1\%) for $1 \mathrm{~d}$ only. The proportion of children being cared for outside the home increased with increasing age.

Table 1. Characteristics by age groups among children participating in the population-based birth cohort of the Type 1 Diabetes Prediction and Prevention nutrition study in Finland

\begin{tabular}{|c|c|c|c|c|c|c|c|c|}
\hline \multirow[b]{2}{*}{ Characteristics } & \multicolumn{2}{|c|}{ 1-year-olds } & \multicolumn{2}{|c|}{ 3-year-olds } & \multicolumn{2}{|c|}{ 6-year-olds } & \multicolumn{2}{|c|}{ All } \\
\hline & $n$ & $\%$ & $n$ & $\%$ & $n$ & $\%$ & $n$ & $\%$ \\
\hline \multicolumn{9}{|l|}{ Sex } \\
\hline Boys & 257 & 56 & 236 & 50 & 364 & 51 & 857 & 52 \\
\hline Girls & 198 & 44 & 235 & 50 & 349 & 49 & 782 & 48 \\
\hline \multicolumn{9}{|l|}{ Region } \\
\hline Southern Finland & 278 & 61 & 297 & 63 & 429 & 60 & 1004 & 61 \\
\hline Northern Finland & 177 & 39 & 174 & 37 & 284 & 40 & 635 & 39 \\
\hline \multicolumn{9}{|l|}{ Number of days recorded } \\
\hline 3 & 439 & 96 & 444 & 94 & 671 & 94 & 1554 & 95 \\
\hline 2 & 15 & 3 & 20 & 4 & 27 & 4 & 62 & 4 \\
\hline 1 & 1 & 0.2 & 7 & 1 & 15 & 2 & 23 & 1 \\
\hline \multicolumn{9}{|l|}{ Day care outside home } \\
\hline No & 405 & 89 & 281 & 60 & 305 & 43 & 991 & 60 \\
\hline Yes & 50 & 11 & 190 & 40 & 408 & 57 & 648 & 40 \\
\hline \multicolumn{9}{|l|}{ Maternal education* } \\
\hline No vocational education & 21 & 5 & 32 & 7 & 29 & 4 & 82 & 5 \\
\hline Vocational school or course & 115 & 25 & 117 & 25 & 194 & 27 & 426 & 26 \\
\hline Upper secondary vocational education & 210 & 46 & 201 & 43 & 341 & 48 & 752 & 46 \\
\hline Academic education & 102 & 22 & 111 & 24 & 139 & 20 & 352 & 22 \\
\hline Missing information & 7 & 2 & 10 & 2 & 10 & 1 & 27 & 2 \\
\hline All & 455 & 100 & 471 & 100 & 713 & 100 & 1639 & 100 \\
\hline
\end{tabular}

(Number of children and percentages)

* At the time of birth of the child. 


\section{Nutrient intake and distribution of intakes}

The nutrient intake of the children is described elsewhere ${ }^{(16)}$. Briefly, energy intake increased with rising age, with the mean intake being higher for boys than for girls. The 1-year-old children had a lower percentage of energy from total fat, SFA and sucrose, and a higher percentage of energy from carbohydrate and PUFA than the other age groups. The nutrient density of the diet for dietary fibre, vitamin $\mathrm{C}$, vitamin $\mathrm{E}$, thiamin, riboflavin, folate, $\mathrm{K}, \mathrm{Fe}$ and $\mathrm{Zn}$ was higher and that of Se was lower among the 1-year-old children than among the older age groups. Log transformation reduced the degree of nonnormality in the distribution of most nutrients with some exceptions. The $D$ values for nutrients with non-normally distributed intakes were lower when log-transformed data were used but, in most of the cases, within $1 \mathrm{~d}$ of the untransformed values.

\section{Variance components}

The ratios of within-subject variances to between-subject variances increased with increasing age. In 1-year-old children, within-subject variance was generally smaller than between-subject variance, and, therefore, ratios of within-subject variances to between-person variances were $<1$ for all nutrients except for cholesterol, vitamin A, $\beta$-carotene and vitamin $\mathrm{B}_{12}$ (Tables 2 and 3). Accordingly, the ratio was $>1$ for thiamin and folate among the boys and for niacin and pyridoxine among the girls. In 3- and 6-year-old children, within-subject variance was greater than between-subject variance. The ratios of within- to between-person variances were $>1$ for all nutrients except for riboflavin for the 3-year-old children and for $\mathrm{P}$ and $\mathrm{Mg}$ for 3-year-old girls (Tables 2 and 3). Overall, the variance ratio was greatest for vitamin $\mathrm{A}$, vitamin $\mathrm{B}_{12}$, folate and cholesterol. There were differences in the ratios between the sexes, the median ratio being higher for girls in every age group. In general, boys had a relatively higher between-subject variance in every age group.

\section{Days required for calculating habitual intakes}

In general, the group requiring the fewest days of records comprised 1-year-old boys, and that requiring the most was 6-year-old girls (Tables 4 and 5). The required number of days was generally slightly higher for the girls than for the boys, with a few exceptions such as for Fe. For the simultaneous assessment of energy and thirteen macronutrients in 1-year-old children, $2 \mathrm{~d}$ food records would be adequate to achieve $r \geq 0.8$, and $4 \mathrm{~d}$ food records to achieve $r \geq 0.9$ except for the assessment of energy and $n-3$ fatty acids in girls for which $5 \mathrm{~d}$ are required (Table 4). The number of required days increases with increasing age; for the assessment of energy ( $r \geq 0 \cdot 9)$, $8 \mathrm{~d}$ are required for 3-year-old children and $11 \mathrm{~d}$ for 6 -year-old children. In all age groups, dietary fibre and protein require fewest days of recording among macronutrients. Among fatty acids, the most days of recording are required for $n-3$ fatty acids, whereas SFA require the least days.

For the simultaneous assessment of twenty micronutrients in 1-year-old children, $3 \mathrm{~d}$ food records would be adequate to achieve $r \geq 0.8$ (Table 5). To achieve $r \geq 0.9$ in 1 -year-old children, a maximum of $7 \mathrm{~d}$ is required for $\beta$-carotene in boys, and $6 \mathrm{~d}$ for $\beta$-carotene, niacin and pyridoxine in girls (Table 5). Among 3- and 6-year-old children, $7 \mathrm{~d}$ food records were found to be sufficient for achieving $r \geq 0.8$ for all other micronutrients except for vitamin $\mathrm{A}$ and $\beta$-carotene. Sevenday food records were observed to be sufficient for accurately ( $r \geq 0 \cdot 9$ ) estimating nine of the twenty reported micronutrients among 3-year-old boys and girls but only two micronutrients among 6-year-old boys and three micronutrients among 6-year-old girls. Vitamin A, $\beta$-carotene and folate intakes require the most replicates (Table 5). Among all the nutrients, a $7 \mathrm{~d}$ food record is sufficient to achieve $r \geq 0.9$ in all age-sex groups only for Ca.

In the DIPP Nutrition Study with $3 \mathrm{~d}$ food records, the correlation coefficients between observed and true intakes of energy and thirty-two reported nutrients averaged 0.91 in 1-year-old children, 0.79 in 3-year-old children and 0.74 in 6 -year-old children. In those 1 -year-old children, the correlation coefficients ranged from 0.81 for $\beta$-carotene (in boys) to 0.96 for vitamin $\mathrm{D}, \mathrm{Ca}$ and $\mathrm{P}$ (in boys). In 3-year-old children, the range was from 0.59 for vitamin A (in boys) to 0.91 for Ca (in girls), and in 6-year-old children from 0.45 for vitamin A (in girls) to 0.83 for vitamin C (in boys) and $\mathrm{Mg}$ (in girls). A $3 \mathrm{~d}$ food record is sufficient to achieve $r$ $\geq 0.9$ for nine macronutrients and twelve micronutrients in 1 -year-old boys, and for eight macronutrients and ten micronutrients in 1-year-old girls. In 3-year-old children, $3 \mathrm{~d}$ food records were found to be sufficient for achieving $r \geq 0.9$ for Ca only, and in 6-year-old children for none of the nutrients.

\section{Dietary supplements}

The most common supplemental nutrient was vitamin $\mathrm{D}$, followed by vitamin $\mathrm{C}$, and, therefore, they were used as example nutrients to study the impact of including the nutrient intake from supplements on variance estimates. The use of vitamin D-containing supplements was most frequent, 86\%, among 1-year-old children, decreasing to $47 \%$ at 3 years and to $21 \%$ at 6 years of age. The use of other supplements increased with increasing age. The proportion of the users of vitamin C-containing supplements was $2 \%$ among 1 -year-old children, increasing to $15 \%$ at 3 years and to $16 \%$ at 6 years. Variance estimates for summed nutrient intakes from food and dietary supplements differed from the estimates for nutrient intake from food according to the proportion of users. If the proportion of supplement users was either very high or very low, there was no remarkable impact on variance estimates (Tables 3 and 5). However, if the proportion of supplement users was medium high, thus increasing the between-person variance of a nutrient of interest, fewer days of food records would be adequate to achieve $r \geq 0.8$ and $\geq 0.9$ compared with days required for calculating habitual intakes from foods only. 
Table 2. Variation in energy and macronutrient intakes by sex and age among children participating in the population-based birth cohort of the Type 1 Diabetes Prediction and Prevention nutrition study in Finland

\begin{tabular}{|c|c|c|c|c|c|c|c|}
\hline \multirow[b]{2}{*}{ Nutrients } & \multirow[b]{2}{*}{ Age (years) } & \multicolumn{2}{|c|}{$\begin{array}{l}\text { Within-subject } \\
\text { variance }\left(S_{\mathrm{w}}^{2}\right)\end{array}$} & \multicolumn{2}{|c|}{$\begin{array}{l}\text { Between-subject } \\
\text { variance }\left(S_{\mathrm{b}}^{2}\right)\end{array}$} & \multicolumn{2}{|c|}{$\begin{array}{c}\text { Within:between } \\
\text { ratio }\end{array}$} \\
\hline & & Boys & Girls & Boys & Girls & Boys & Girls \\
\hline \multirow[t]{3}{*}{ Energy } & 1 & 288228 & 220180 & 339195 & 227912 & 0.85 & 0.97 \\
\hline & 3 & 975956 & 1068230 & 584171 & 577329 & 1.67 & 1.85 \\
\hline & 6 & 1840755 & 1336166 & 702531 & 689787 & $2 \cdot 62$ & 1.94 \\
\hline \multirow[t]{3}{*}{ Protein } & 1 & 40 & 45 & 98 & 53 & 0.41 & 0.85 \\
\hline & 3 & 133 & 110 & 95 & 95 & 1.41 & $1 \cdot 16$ \\
\hline & 6 & 209 & 165 & 98 & 96 & $2 \cdot 12$ & 1.73 \\
\hline \multirow[t]{3}{*}{ Carbohydrates } & 1 & 336 & 259 & 368 & 322 & 0.91 & 0.80 \\
\hline & 3 & 1249 & 1315 & 772 & 541 & 1.62 & 2.43 \\
\hline & 6 & 2350 & 1771 & 674 & 796 & 3.49 & $2 \cdot 23$ \\
\hline \multirow[t]{3}{*}{ Starch } & 1 & 169 & 110 & 252 & 248 & 0.67 & 0.44 \\
\hline & 3 & 451 & 397 & 229 & 212 & 1.97 & 1.87 \\
\hline & 6 & 781 & 574 & 276 & 251 & 2.83 & $2 \cdot 28$ \\
\hline \multirow[t]{3}{*}{ Total sugars } & 1 & 150 & 139 & 279 & 218 & 0.54 & 0.64 \\
\hline & 3 & 591 & 705 & 531 & 280 & 1.11 & $2 \cdot 52$ \\
\hline & 6 & 1123 & 887 & 404 & 421 & $2 \cdot 78$ & $2 \cdot 11$ \\
\hline \multirow[t]{3}{*}{ Sucrose } & 1 & 58 & 47 & 62 & 45 & 0.93 & 1.04 \\
\hline & 3 & 335 & 400 & 212 & 134 & 1.58 & 2.98 \\
\hline & 6 & 620 & 508 & 190 & 200 & $3 \cdot 26$ & 2.54 \\
\hline \multirow[t]{3}{*}{ Fibre } & 1 & $4 \cdot 1$ & 3.9 & 8.9 & $8 \cdot 8$ & 0.46 & 0.44 \\
\hline & 3 & $8 \cdot 6$ & $7 \cdot 1$ & $5 \cdot 7$ & $6 \cdot 0$ & 1.52 & $1 \cdot 18$ \\
\hline & 6 & 13 & 13 & 10 & $6 \cdot 3$ & 1.35 & $2 \cdot 00$ \\
\hline \multirow[t]{3}{*}{ Fat } & 1 & 44 & 29 & 66 & 42 & 0.66 & 0.68 \\
\hline & 3 & 176 & 178 & 92 & 94 & 1.92 & 1.89 \\
\hline & 6 & 312 & 249 & 133 & 78 & 2.35 & $3 \cdot 18$ \\
\hline \multirow[t]{3}{*}{ SFA } & 1 & 10 & $8 \cdot 1$ & 16 & 12 & 0.63 & 0.69 \\
\hline & 3 & 39 & 40 & 22 & 22 & 1.79 & 1.81 \\
\hline & 6 & 70 & 57 & 36 & 22 & 1.95 & $2 \cdot 58$ \\
\hline \multirow[t]{3}{*}{ MUFA } & 1 & $7 \cdot 7$ & $4 \cdot 8$ & $11 \cdot 3$ & $7 \cdot 6$ & 0.68 & 0.63 \\
\hline & 3 & 25 & 25 & 16 & 12 & 1.53 & 1.99 \\
\hline & 6 & 43 & 34 & 17 & $9 \cdot 8$ & $2 \cdot 49$ & $3 \cdot 51$ \\
\hline \multirow[t]{3}{*}{ PUFA } & 1 & $2 \cdot 0$ & 1.3 & $4 \cdot 8$ & 2.9 & 0.41 & 0.45 \\
\hline & 3 & $6 \cdot 3$ & $5 \cdot 1$ & $4 \cdot 1$ & $2 \cdot 2$ & 1.56 & $2 \cdot 34$ \\
\hline & 6 & 11 & 7.9 & 3.3 & $7 \cdot 0$ & 3.35 & 3.96 \\
\hline \multirow[t]{3}{*}{$n-6$ Fatty acids } & 1 & 1.4 & 0.9 & 3.4 & $2 \cdot 3$ & 0.42 & 0.39 \\
\hline & 3 & $4 \cdot 2$ & 3.5 & 2.5 & 1.2 & 1.66 & $2 \cdot 84$ \\
\hline & 6 & 7.4 & 5.4 & $2 \cdot 1$ & 1.3 & 3.58 & 4.23 \\
\hline \multirow[t]{3}{*}{$n-3$ Fatty acids } & 1 & 0.18 & 0.1 & 0.18 & 0.1 & 0.99 & 1.07 \\
\hline & 3 & 0.5 & 0.3 & 0.2 & 0.1 & 2.08 & 2.43 \\
\hline & 6 & 0.7 & 0.5 & 0.2 & 0.1 & 4.35 & 4.43 \\
\hline \multirow[t]{3}{*}{ Cholesterol } & 1 & 1126 & 1111 & 994 & 563 & $1 \cdot 13$ & 1.97 \\
\hline & 3 & 4852 & 4598 & 1058 & 1290 & 4.59 & 3.56 \\
\hline & 6 & 6843 & 6785 & 1244 & 806 & 5.50 & 8.42 \\
\hline
\end{tabular}

${ }^{*}$ A linear mixed model was used to estimate $S_{\mathrm{w}}^{2}$ and $S_{\mathrm{b}}^{2}$ separately in every sex and age group. Ratios of within- and between-subject variances are expressed as $S_{\mathrm{w}}^{2}: S_{\mathrm{b}}^{2}$.

\section{Discussion}

The nutrient intake variability in children belonging to the DIPP study cohort was estimated at the ages of 1,3 and 6 years, and the number of daily food records required to estimate intake of energy and thirty-two nutrients is presented. Important differences for variance components by age and sex were demonstrated. The ratio of within-subject variances to between-subject variances increases within increasing age, and is slightly higher in girls than in boys. Fewer days are required for estimating intakes in 1-year-old children compared with older ones. The highest number of days required was found for vitamin A, cholesterol, $n-3$ and n-6 fatty acids, $\beta$-carotene and folate. The correlation coefficients between observed and true intakes of energy and dietary factors based on $3 \mathrm{~d}$ food records generally lie above 0.8 in those 1-year-old children, and above 0.7 in 3-and 6-year-old children. Including supplemental intake has an impact on the variance estimates according to the proportion of supplement users.

Among 1-year-old children, the within-subject variance to between-subject variance ratios were generally $<1$. Infant feeding practices encompass a series of age-specific, interrelated behaviours followed by a transfer to start partaking in family meals after the age of 1 year when most complementary foods are introduced ${ }^{(17)}$. Due to dramatic changes in food patterns during the first years of life, combined with significant individual variation in the timing of these changes, there is a greater between-subject variance among 1-year-old children than among older children. Persistent eating behaviours and particular dietary patterns could be seen by the age of 2-3 years $^{(18,19)}$, and, accordingly, an increased magnitude of 
Table 3. Variation in micronutrient intake by sex and age among children participating in the population-based birth cohort of the Type 1 Diabetes Prediction and Prevention nutrition study in Finland*

\begin{tabular}{|c|c|c|c|c|c|c|c|}
\hline \multirow[b]{2}{*}{ Nutrients } & \multirow[b]{2}{*}{ Age (years) } & \multicolumn{2}{|c|}{$\begin{array}{l}\text { Within-subject } \\
\text { variance }\left(S_{\mathrm{w}}^{2}\right)\end{array}$} & \multicolumn{2}{|c|}{$\begin{array}{l}\text { Between-subject } \\
\text { variance }\left(S_{\mathrm{b}}^{2}\right)\end{array}$} & \multicolumn{2}{|c|}{$\begin{array}{c}\text { Within:between } \\
\text { ratio }\end{array}$} \\
\hline & & Boys & Girls & Boys & Girls & Boys & Girls \\
\hline \multirow[t]{3}{*}{ Vitamin A } & 1 & 178113 & 97190 & 23350 & 25781 & 7.63 & 3.77 \\
\hline & 3 & 1050853 & 904767 & 5184 & 103749 & 203 & 8.72 \\
\hline & 6 & 1232150 & 1012636 & 27261 & 66008 & $45 \cdot 20$ & $15 \cdot 34$ \\
\hline \multirow[t]{3}{*}{$\beta$-Carotene } & 1 & 2639537 & 2499203 & 2072679 & 1743294 & 1.27 & 1.43 \\
\hline & 3 & 3100132 & 2908979 & 413287 & 1351274 & $7 \cdot 50$ & $2 \cdot 15$ \\
\hline & 6 & 3048428 & 3592127 & 1177758 & 582430 & 2.59 & $6 \cdot 17$ \\
\hline \multirow[t]{3}{*}{ Vitamin D from food } & 1 & 4.7 & 3.0 & 11 & 10 & 0.41 & 0.29 \\
\hline & 3 & 8.5 & $5 \cdot 7$ & $2 \cdot 3$ & $1 \cdot 2$ & 3.74 & 4.83 \\
\hline & 6 & 7.9 & $6 \cdot 6$ & 1.8 & 1.4 & 4.38 & 4.69 \\
\hline \multirow[t]{3}{*}{ Vitamin D from food and supplements } & 1 & 11 & 8.4 & 17 & $18 \cdot 2$ & 0.62 & 0.46 \\
\hline & 3 & 16 & 11 & 14 & 16 & $1 \cdot 12$ & 0.72 \\
\hline & 6 & 12 & 11 & $8 \cdot 3$ & $6 \cdot 4$ & 1.44 & 1.72 \\
\hline \multirow[t]{3}{*}{ Vitamin E } & 1 & 0.95 & 0.75 & $2 \cdot 5$ & $1 \cdot 6$ & 0.38 & 0.47 \\
\hline & 3 & $2 \cdot 4$ & 1.93 & 1.4 & 0.80 & 1.76 & 2.42 \\
\hline & 6 & $4 \cdot 8$ & 3.5 & 1.07 & $1 \cdot 1$ & 4.50 & $3 \cdot 16$ \\
\hline \multirow[t]{3}{*}{ Thiamin } & 1 & 0.03 & 0.02 & 0.03 & 0.02 & $1 \cdot 15$ & 0.92 \\
\hline & 3 & 0.09 & 0.06 & 0.04 & 0.04 & $2 \cdot 26$ & 1.42 \\
\hline & 6 & 0.14 & 0.11 & 0.05 & 0.03 & $2 \cdot 79$ & 4.42 \\
\hline \multirow[t]{3}{*}{ Riboflavin } & 1 & 0.05 & 0.05 & 0.15 & 0.12 & 0.36 & 0.41 \\
\hline & 3 & 0.17 & 0.14 & 0.18 & 0.17 & 0.97 & 0.82 \\
\hline & 6 & 0.26 & 0.21 & 0.15 & 0.13 & 1.76 & 1.71 \\
\hline \multirow[t]{3}{*}{ Niacin } & 1 & $5 \cdot 6$ & 4.7 & $9 \cdot 2$ & 3.8 & 0.61 & 1.25 \\
\hline & 3 & 19 & 13 & 8.7 & 11 & $2 \cdot 13$ & 1.21 \\
\hline & 6 & 28 & 22 & 13 & 11 & $2 \cdot 20$ & 2.08 \\
\hline Pyridoxine & 1 & 0.05 & 0.05 & 0.07 & 0.05 & 0.78 & $1 \cdot 13$ \\
\hline & 3 & 0.15 & 0.12 & 0.09 & 0.07 & 1.75 & 1.78 \\
\hline & 6 & 0.21 & 0.16 & 0.08 & 0.08 & $2 \cdot 54$ & 2.03 \\
\hline Folate & 1 & 1201 & 530 & 587 & 596 & 2.05 & 0.89 \\
\hline & 3 & 3532 & 2542 & 242 & 780 & 14.63 & 3.26 \\
\hline & 6 & 4917 & 4478 & 1083 & 703 & 4.54 & $6 \cdot 37$ \\
\hline Vitamin $B_{12}$ & 1 & 1.5 & $1 \cdot 3$ & 0.99 & 0.80 & 1.54 & 1.62 \\
\hline & 3 & 12 & 10 & $1 \cdot 8$ & $1 \cdot 7$ & $15 \cdot 6$ & 5.83 \\
\hline & 6 & 17 & 13 & 1.6 & 1.4 & $10 \cdot 48$ & 9.49 \\
\hline Vitamin $\mathrm{C}$ from food & 1 & 550 & 607 & 971 & 692 & 0.57 & 0.88 \\
\hline & 3 & 1550 & 1167 & 891 & 653 & 1.74 & 1.79 \\
\hline & 6 & 1682 & 1345 & 1127 & 624 & 1.49 & $2 \cdot 15$ \\
\hline Vitamin C from food and supplements & 1 & 550 & 607 & 971 & 713 & 0.57 & 0.85 \\
\hline & 3 & 2141 & 1266 & 1228 & 999 & 1.74 & 1.27 \\
\hline & 6 & 2298 & 1489 & 1593 & 818 & 1.44 & 1.82 \\
\hline $\mathrm{K}$ & 1 & 96857 & 89414 & 222685 & 160376 & 0.44 & 0.56 \\
\hline & 3 & 325487 & 219759 & 246972 & 199925 & 1.32 & $1 \cdot 10$ \\
\hline & 6 & 448396 & 368488 & 238930 & 212041 & $1 \cdot 88$ & 1.74 \\
\hline $\mathrm{Ca}$ & 1 & 21186 & 20897 & 80163 & 65717 & 0.26 & 0.32 \\
\hline & 3 & 73149 & 58967 & 75294 & 71827 & 0.97 & 0.82 \\
\hline & 6 & 101214 & 83384 & 63154 & 58811 & 1.60 & 1.42 \\
\hline $\mathrm{P}$ & 1 & 16264 & 17259 & 56418 & 40658 & 0.29 & 0.42 \\
\hline & 3 & 57703 & 45406 & 48744 & 50587 & $1 \cdot 18$ & 0.90 \\
\hline & 6 & 79219 & 68023 & 46967 & 49499 & 1.69 & 1.37 \\
\hline $\mathrm{Fe}$ & 1 & 3.3 & 1.6 & 3.9 & 3.5 & 0.84 & 0.45 \\
\hline & 3 & 5.9 & 4.1 & 1.4 & 1.7 & 4.37 & 2.44 \\
\hline & 6 & 14 & 11 & $2 \cdot 0$ & $4 \cdot 1$ & 6.95 & 2.68 \\
\hline $\mathrm{Mg}$ & 1 & 756 & 647 & 1490 & 1111 & 0.51 & 0.58 \\
\hline & 3 & 1915 & 1369 & 1477 & 1471 & $1 \cdot 30$ & 0.93 \\
\hline & 6 & 2770 & 2245 & 1559 & 1626 & $1 \cdot 78$ & 1.38 \\
\hline $\mathrm{Zn}$ & 1 & 1.7 & 1.3 & 2.0 & 1.2 & 0.85 & 1.09 \\
\hline & 3 & 3.5 & $2 \cdot 6$ & 1.6 & 1.9 & $2 \cdot 18$ & 1.42 \\
\hline & 6 & $4 \cdot 8$ & 4.0 & $1 \cdot 8$ & $2 \cdot 2$ & $2 \cdot 67$ & 1.82 \\
\hline $\mathrm{Se}$ & 1 & 32 & 34 & 53 & 24 & 0.60 & 1.41 \\
\hline & 3 & 116 & 83 & 36 & 55 & 3.20 & 1.50 \\
\hline & 6 & 163 & 141 & 54 & 45 & 3.03 & $3 \cdot 11$ \\
\hline I & 1 & 747 & 691 & 1700 & 1262 & 0.44 & 0.55 \\
\hline & 3 & 2310 & 1785 & 1853 & 1827 & 1.25 & 0.98 \\
\hline & 6 & 3730 & 2792 & 1405 & 1831 & $2 \cdot 66$ & 1.53 \\
\hline
\end{tabular}

${ }^{\star}$ A linear mixed model was used to estimate $S_{\mathrm{w}}^{2}$ and $S_{\mathrm{b}}^{2}$ separately in every sex and age group. Ratios of within- and between-subject variances are expressed as $S_{\mathrm{w}}^{2}: S_{\mathrm{b}}^{2}$. 
Table 4. Macronutrients; calculated number of days $(D)$ needed to ensure $r \geq 0.80$ and $\geq 0.90$ and $r$ for $3 \mathrm{~d}$ by age among boys and girls participating in the population-based birth cohort of the Type 1 Diabetes Prediction and Prevention nutrition study in Finland*

\begin{tabular}{|c|c|c|c|c|c|c|c|}
\hline \multirow[b]{2}{*}{ Nutrients } & \multirow[b]{2}{*}{ Age (years) } & \multicolumn{2}{|c|}{$D(r \geq 0.80)$} & \multicolumn{2}{|c|}{$D(r \geq 0.90)$} & \multicolumn{2}{|c|}{$r$ for $3 d$} \\
\hline & & Boys & Girls & Boys & Girls & Boys & Girls \\
\hline \multirow[t]{3}{*}{ Energy } & 1 & 2 & 2 & 4 & 5 & 0.88 & 0.87 \\
\hline & 3 & 3 & 4 & 8 & 8 & 0.80 & 0.79 \\
\hline & 6 & $5 \dagger$ & 4 & $11 \dagger$ & 9 & $0.75 \dagger$ & 0.78 \\
\hline \multirow[t]{3}{*}{ Protein } & 1 & $1 \ddagger$ & 2 & $2 \ddagger$ & 4 & $0.94 \ddagger$ & 0.88 \\
\hline & 3 & 3 & $3 \ddagger$ & 6 & $6 \ddagger$ & 0.83 & $0.83 \ddagger$ \\
\hline & 6 & 4 & 3 & 9 & 8 & 0.77 & 0.80 \\
\hline \multirow[t]{3}{*}{ Carbohydrates } & 1 & 2 & $2 \ddagger$ & 4 & $4 \ddagger$ & 0.88 & $0.89 \ddagger$ \\
\hline & 3 & 3 & 5 & 7 & 11 & 0.81 & 0.74 \\
\hline & 6 & $6 \ddagger$ & 4 & $14 \ddagger$ & 10 & $0.70 \ddagger$ & 0.76 \\
\hline \multirow[t]{3}{*}{ Starch } & 1 & 2 & $1 \dagger$ & 3 & $2 \dagger$ & 0.90 & $0.93 \dagger$ \\
\hline & 3 & $4 \dagger$ & $4 \dagger$ & $8 \dagger$ & $10 \dagger$ & $0.79 \dagger$ & $0.76 \dagger$ \\
\hline & 6 & 5 & 4 & 12 & 10 & 0.72 & 0.75 \\
\hline \multirow[t]{3}{*}{ Total sugars } & 1 & 1 & 2 & 3 & 3 & 0.92 & 0.91 \\
\hline & 3 & $2 \ddagger$ & 5 & $5 \ddagger$ & 11 & $0.85 \ddagger$ & 0.74 \\
\hline & 6 & $5 \ddagger$ & $4 \dagger$ & $11 \ddagger$ & $9 \dagger$ & $0.73 \ddagger$ & $0.77 \dagger$ \\
\hline \multirow[t]{3}{*}{ Sucrose } & 1 & $2 \ddagger$ & $2 \ddagger$ & $4 \ddagger$ & $4 \ddagger$ & $0.88 \ddagger$ & $0.88 \ddagger$ \\
\hline & 3 & $4 \ddagger$ & $6 \dagger$ & $9 \ddagger$ & $14 \dagger$ & $0.77 \ddagger$ & $0.69 \dagger$ \\
\hline & 6 & $5 \dagger$ & $5 \ddagger$ & $12 \dagger$ & $13 \ddagger$ & $0.72 \dagger$ & $0.72 \ddagger$ \\
\hline \multirow[t]{3}{*}{ Fibre } & 1 & 1 & $1 \dagger$ & 2 & $3 \dagger$ & 0.93 & $0.93 \dagger$ \\
\hline & 3 & $3 \dagger$ & 3 & $7 \dagger$ & 5 & $0.82 \dagger$ & 0.85 \\
\hline & 6 & $3 \ddagger$ & $4 \dagger$ & $7 \ddagger$ & $10 \dagger$ & $0.81 \ddagger$ & $0.75 \dagger$ \\
\hline \multirow[t]{3}{*}{ Fat } & 1 & 2 & 2 & 3 & 3 & 0.91 & 0.90 \\
\hline & 3 & $4 \ddagger$ & $5 \ddagger$ & $8 \ddagger$ & $10 \ddagger$ & $0.79 \ddagger$ & $0.75 \ddagger$ \\
\hline & 6 & $5 \ddagger$ & $6 \dagger$ & $11 \ddagger$ & $14 \dagger$ & $0.74 \ddagger$ & $0.70 \dagger$ \\
\hline \multirow[t]{3}{*}{ SFA } & 1 & $1 \dagger$ & $1 \dagger$ & $2 \dagger$ & $3 \dagger$ & $0.93 \dagger$ & $0.91 \dagger$ \\
\hline & 3 & 4 & $4 \ddagger$ & 8 & $8 \ddagger$ & 0.79 & $0.79 \ddagger$ \\
\hline & 6 & $4 \dagger$ & $5 \ddagger$ & $8 \dagger$ & $11 \ddagger$ & $0.79 \dagger$ & $0.73 \ddagger$ \\
\hline \multirow[t]{3}{*}{ MUFA } & 1 & 2 & 2 & 3 & 3 & 0.90 & 0.91 \\
\hline & 3 & $3 \ddagger$ & $5 \ddagger$ & $8 \ddagger$ & $11 \ddagger$ & $0.80 \ddagger$ & $0.74 \ddagger$ \\
\hline & 6 & $5 \dagger$ & 7 & $12 \dagger$ & 15 & $0.73 \dagger$ & 0.68 \\
\hline \multirow[t]{3}{*}{ PUFA } & 1 & $1 \dagger$ & 1 & $2 \dagger$ & 2 & $0.93 \dagger$ & 0.93 \\
\hline & 3 & $4 \dagger$ & $5 \ddagger$ & $9 \dagger$ & $12 \ddagger$ & $0.77 \dagger$ & $0.73 \ddagger$ \\
\hline & 6 & $6 \dagger$ & 7 & $13 \dagger$ & 17 & $0.71 \dagger$ & 0.66 \\
\hline \multirow[t]{3}{*}{$n-6$ Fatty acids } & 1 & $1 \dagger$ & 1 & $3 \dagger$ & 2 & $0.92 \dagger$ & 0.94 \\
\hline & 3 & $5 \dagger$ & $6 \ddagger$ & $10 \dagger$ & $13 \ddagger$ & $0.75 \dagger$ & $0.71 \neq$ \\
\hline & 6 & $6 \ddagger$ & 8 & $14 \ddagger$ & 18 & $0.70 \ddagger$ & 0.64 \\
\hline \multirow[t]{3}{*}{ n-3 Fatty acids } & 1 & $2 \dagger$ & 2 & $4 \dagger$ & 5 & $0.88 \dagger$ & 0.86 \\
\hline & 3 & $5 \ddagger$ & $5 \ddagger$ & $11 \ddagger$ & $12 \ddagger$ & $0.75 \ddagger$ & $0.73 \ddagger$ \\
\hline & 6 & $7 \dagger$ & $8 \dagger$ & $15 \dagger$ & $19 \dagger$ & $0.68 \dagger$ & $0.64 \dagger$ \\
\hline \multirow[t]{3}{*}{ Cholesterol } & 1 & $2 \dagger$ & $2 \dagger$ & $4 \dagger$ & $4 \dagger$ & $0.90 \dagger$ & $0.87 \dagger$ \\
\hline & 3 & $5 \dagger$ & $5 \ddagger$ & $10 \dagger$ & $10 \ddagger$ & $0.75 \dagger$ & $0.75 \ddagger$ \\
\hline & 6 & $7 \ddagger$ & $9 \ddagger$ & $16 \ddagger$ & $20 \ddagger$ & $0.67 \ddagger$ & $0.63 \ddagger$ \\
\hline
\end{tabular}

* The number of days $(D)$ of food records needed to obtain the required $r$ of 0.9 and 0.8 between observedand true-nutrient intakes was calculated using the following formula: $D=\left(\left(r^{2}\right) /\left(1-r^{2}\right)\right) \times\left(S_{\mathrm{w}}^{2} / S_{\mathrm{b}}^{2}\right)$. The following formula was used to determine the level of accuracy with $3 \mathrm{~d}$ of recording: $r=\left(D /\left(D+S_{w}^{2} / S_{b}^{2}\right)\right)^{1 / 2}$.

† Based on log-transformed data that do not fully follow a normal distribution.

‡Based on log-transformed data.

within-subject variance. If the size of the day-to-day variation in subjects' intakes is small compared with the size of the difference between subjects, then fewer days of food record are needed. This is seen in $D$ values, which were generally lower for 1-year-old children. Among the 3- and 6-year-old children, the within-subject variance to between-subject variance ratios were generally $>1$, as has been reported in other studies $^{(5,10)}$. This implies that diversity of foods eaten increases rapidly after the child starts partaking in family meals. Accordingly, it might be more difficult to find epidemiological associations with health outcomes among older age groups of children than among 1-year-old children because associations are more difficult to detect when ratios of within-subject variance and between-subject variance exceed unity ${ }^{(7)}$.

The $D$ values depended ultimately on the chosen $r$ and the ratio of the within-subject variances to between-subject variances. In the DIPP study, the correlation coefficients between observed and true intakes of energy and dietary factors based on $3 \mathrm{~d}$ food records lie generally above 0.8 in 1-year-old children and above 0.7 in those 3- and 6-year-old children. As $r$ increases, then the proportion of subjects correctly classified also increases, while the proportion of subjects grossly misclassified decreases. When observing $D$ and $r$ values for 
Table 5. Micronutrients; calculated number of days $(D)$ needed to ensure $r \geq 0.80$ and $\geq 0.90$ and $r$ for $3 \mathrm{~d}$ by age among boys and girls participating in the population-based birth cohort of the Type 1 Diabetes Prediction and Prevention nutrition study in Finland*

\begin{tabular}{|c|c|c|c|c|c|c|c|}
\hline \multirow[b]{2}{*}{ Nutrients } & \multirow[b]{2}{*}{ Age (years) } & \multicolumn{2}{|c|}{$D(r \geq 0.80)$} & \multicolumn{2}{|c|}{$D(r \geq 0.90)$} & \multicolumn{2}{|c|}{$r$ for $3 d$} \\
\hline & & Boys & Girls & Boys & Girls & Boys & Girls \\
\hline \multirow[t]{3}{*}{ Vitamin A } & 1 & $2 \dagger$ & $2 \dagger$ & $5 \dagger$ & $4 \dagger$ & $0.86 \dagger$ & $0.89 \dagger$ \\
\hline & 3 & $10 \ddagger$ & $9 \dagger$ & $24 \ddagger$ & $21 \dagger$ & $0.59 \ddagger$ & $0.62 \dagger$ \\
\hline & 6 & $9 \dagger$ & $21 \dagger$ & $22 \dagger$ & $50 \dagger$ & $0.61 \dagger$ & $0.45 \dagger$ \\
\hline \multirow[t]{3}{*}{$\beta$-Carotene } & 1 & $3 \ddagger$ & $3 \dagger$ & $7 \ddagger$ & $6 \dagger$ & $0.81 \ddagger$ & $0.83 \dagger$ \\
\hline & 3 & $6 \neq$ & $6 \ddagger$ & $14 \ddagger$ & $13 \ddagger$ & $0.70 \ddagger$ & $0 \cdot 71 \ddagger$ \\
\hline & 6 & $5 \ddagger$ & $8 \ddagger$ & $11 \ddagger$ & $19 \ddagger$ & $0.74 \ddagger$ & $0.64 \ddagger$ \\
\hline \multirow[t]{3}{*}{ Vitamin D from food } & 1 & $1 \dagger$ & $1 \dagger$ & $2 \dagger$ & $1 \dagger$ & $0.95 \dagger$ & $0.96 \dagger$ \\
\hline & 3 & $3+$ & $4 \dagger$ & $5 \dagger$ & $8 \dagger$ & $0.85 \dagger$ & $0.79 \dagger$ \\
\hline & 6 & $5 \dagger$ & $4 \dagger$ & $11 \dagger$ & $9 \dagger$ & $0.74 \dagger$ & $0.77 \dagger$ \\
\hline \multirow[t]{3}{*}{ Vitamin D from food and supplements } & 1 & 1 & 1 & 3 & 2 & 0.91 & 0.93 \\
\hline & 3 & $2 \ddagger$ & $2 \dagger$ & $5 \ddagger$ & $3 \dagger$ & $0.85 \ddagger$ & $0.90 \dagger$ \\
\hline & 6 & $3 \dagger$ & $3 \dagger$ & $7 \dagger$ & $7 \dagger$ & $0.81 \dagger$ & $0.81 \dagger$ \\
\hline \multirow[t]{3}{*}{ Vitamin E } & 1 & $1 \dagger$ & 1 & $2 \dagger$ & 2 & $0.95 \dagger$ & 0.93 \\
\hline & 3 & $4 \ddagger$ & $6 \ddagger$ & $9 \ddagger$ & $13 \ddagger$ & $0.77 \ddagger$ & $0.71 \ddagger$ \\
\hline & 6 & $7 \ddagger$ & $6 \dagger$ & $16 \ddagger$ & $13 \dagger$ & $0.68 \ddagger$ & $0.70 \dagger$ \\
\hline \multirow[t]{3}{*}{ Thiamin } & 1 & $2 \ddagger$ & $2 \ddagger$ & $4 \ddagger$ & $5 \ddagger$ & $0.88 \ddagger$ & $0.87 \ddagger$ \\
\hline & 3 & $4 \ddagger$ & $4 \ddagger$ & $9 \ddagger$ & $8 \ddagger$ & $0.77 \ddagger$ & $0.79 \ddagger$ \\
\hline & 6 & $5 \ddagger$ & $7 \ddagger$ & $12 \ddagger$ & $16 \ddagger$ & $0.73 \ddagger$ & $0.67 \ddagger$ \\
\hline \multirow[t]{3}{*}{ Riboflavin } & 1 & 1 & 1 & 2 & 2 & 0.94 & 0.94 \\
\hline & 3 & 2 & 2 & 5 & 4 & 0.87 & 0.89 \\
\hline & 6 & 4 & 3 & 8 & 8 & 0.79 & $0 \cdot 80$ \\
\hline \multirow[t]{3}{*}{ Niacin } & 1 & $1 \neq$ & 3 & $3 \ddagger$ & 6 & $0.92 \ddagger$ & 0.84 \\
\hline & 3 & $4 \ddagger$ & $3 \ddagger$ & $9 \ddagger$ & $7 \ddagger$ & $0.78 \ddagger$ & $0.82 \ddagger$ \\
\hline & 6 & $4 \ddagger$ & 4 & $9 \ddagger$ & 9 & $0.77 \ddagger$ & 0.77 \\
\hline Pyridoxine & 1 & $2 \ddagger$ & $3 \ddagger$ & $4 \ddagger$ & $6 \ddagger$ & $0.89 \ddagger$ & $0.83 \ddagger$ \\
\hline & 3 & $3 \ddagger$ & $4 \ddagger$ & $7 \ddagger$ & $8 \ddagger$ & $0.82 \ddagger$ & $0.79 \ddagger$ \\
\hline & 6 & $4 \ddagger$ & $4 \dagger$ & $9 \ddagger$ & $9 \dagger$ & $0.77 \ddagger$ & $0.77 \dagger$ \\
\hline Folate & 1 & $2 \ddagger$ & $2 \dagger$ & $4 \ddagger$ & $4 \dagger$ & $0.89 \ddagger$ & $0.89 \dagger$ \\
\hline & 3 & $8 \ddagger$ & $4 \ddagger$ & $18 \ddagger$ & $10 \ddagger$ & $0.65 \ddagger$ & $0.75 \ddagger$ \\
\hline & 6 & $5 \ddagger$ & $7 \ddagger$ & $11 \ddagger$ & $15 \ddagger$ & $0.74 \ddagger$ & $0.68 \ddagger$ \\
\hline Vitamin $B_{12}$ & 1 & $1 \neq$ & $2 \ddagger$ & $2 \ddagger$ & $4 \ddagger$ & $0.94 \ddagger$ & $0.90 \ddagger$ \\
\hline & 3 & $4 \dagger$ & $4 \dagger$ & $10 \dagger$ & $8 \dagger$ & $0.75 \dagger$ & $0.79 \dagger$ \\
\hline & 6 & $6 \dagger$ & $6 \dagger$ & $13 \dagger$ & $15 \dagger$ & $0.71 \dagger$ & $0.68 \dagger$ \\
\hline Vitamin C from food & 1 & $1 \dagger$ & 2 & $3 \dagger$ & 4 & $0.93 \dagger$ & 0.88 \\
\hline & 3 & $3 \ddagger$ & $3 \ddagger$ & $6 \ddagger$ & $7 \ddagger$ & $0.84 \ddagger$ & $0.81 \ddagger$ \\
\hline & 6 & $3 \ddagger$ & $4 \ddagger$ & $6 \ddagger$ & $9 \ddagger$ & $0.83 \ddagger$ & $0.78 \ddagger$ \\
\hline Vitamin C from food and supplements & 1 & $1 \dagger$ & 2 & $3 \dagger$ & 4 & $0.93 \dagger$ & 0.88 \\
\hline & 3 & $2 \ddagger$ & $3 \ddagger$ & $5 \ddagger$ & $6 \ddagger$ & $0.85 \ddagger$ & $0.83 \ddagger$ \\
\hline & 6 & $3 \ddagger$ & $4 \ddagger$ & $6 \ddagger$ & $8 \ddagger$ & $0.83 \ddagger$ & $0.79 \ddagger$ \\
\hline $\mathrm{K}$ & 1 & 2 & 1 & 5 & 3 & 0.86 & 0.92 \\
\hline & 3 & 3 & $3 \ddagger$ & 6 & $6 \ddagger$ & 0.83 & $0.84 \ddagger$ \\
\hline & 6 & 4 & 3 & 8 & 8 & 0.78 & 0.80 \\
\hline $\mathrm{Ca}$ & 1 & $1 \dagger$ & $1 \dagger$ & $1 \dagger$ & $2 \dagger$ & $0.96 \dagger$ & $0.95 \dagger$ \\
\hline & 3 & 2 & $2 \dagger$ & 5 & $3+$ & 0.87 & $0.91 \dagger$ \\
\hline & 6 & 3 & 3 & 7 & 6 & 0.81 & 0.82 \\
\hline$P$ & 1 & $1 \dagger$ & $1 \ddagger$ & $2 \dagger$ & $2 \ddagger$ & $0.96 \dagger$ & $0.94 \ddagger$ \\
\hline & 3 & 3 & $2 \ddagger$ & 5 & $5 \ddagger$ & 0.85 & $0.87 \ddagger$ \\
\hline & 6 & 3 & $3 \dagger$ & 8 & $8 \dagger$ & 0.80 & $0.80 \dagger$ \\
\hline $\mathrm{Fe}$ & 1 & $2 \ddagger$ & $1 \ddagger$ & $3 \ddagger$ & $3 \ddagger$ & $0.91 \ddagger$ & $0.92 \ddagger$ \\
\hline & 3 & $5 \ddagger$ & $4 \ddagger$ & $12 \ddagger$ & $8 \ddagger$ & $0.72 \ddagger$ & $0.78 \ddagger$ \\
\hline & 6 & $8 \ddagger$ & $5 \dagger$ & $18 \ddagger$ & $10 \dagger$ & $0.65 \ddagger$ & $0.75 \dagger$ \\
\hline $\mathrm{Mg}$ & 1 & 1 & 1 & 3 & 3 & 0.92 & 0.92 \\
\hline & 3 & 3 & 2 & 6 & 4 & 0.84 & 0.87 \\
\hline & 6 & 4 & 3 & 8 & 6 & 0.79 & 0.83 \\
\hline $\mathrm{Zn}$ & 1 & $2 \ddagger$ & 2 & $4 \ddagger$ & 5 & $0.89 \ddagger$ & 0.86 \\
\hline & 3 & 4 & 3 & 10 & 6 & 0.76 & 0.82 \\
\hline & 6 & 5 & $4 \dagger$ & 12 & $10 \dagger$ & 0.73 & $0.76 \dagger$ \\
\hline $\mathrm{Se}$ & 1 & $1 \dagger$ & $2 \dagger$ & $3 \dagger$ & $5 \dagger$ & $0.91 \dagger$ & $0.85 \dagger$ \\
\hline & 3 & $5 \ddagger$ & $3 \ddagger$ & $11 \ddagger$ & $8 \ddagger$ & $0.74 \ddagger$ & $0.80 \ddagger$ \\
\hline & 6 & $6 \ddagger$ & 6 & $13 \ddagger$ & 14 & $0.71 \neq$ & 0.70 \\
\hline 1 & 1 & $1 \neq$ & 1 & $2 \ddagger$ & 2 & $0.95 \ddagger$ & 0.93 \\
\hline & 3 & $3 \neq$ & $2 \ddagger$ & $6 \ddagger$ & $5 \ddagger$ & $0.84 \ddagger$ & $0.87 \ddagger$ \\
\hline & 6 & 5 & 3 & 12 & 7 & 0.73 & 0.81 \\
\hline
\end{tabular}

* The number of days $(D)$ of food records needed to obtain the required $r$ of 0.9 and 0.8 between observed- and true-nutrient intakes was calculated using the following formula: $D=\left(\left(r^{2}\right) /\left(1-r^{2}\right)\right) \times\left(S_{w}^{2} / S_{b}^{2}\right)$. The following formula was used to determine the level of accuracy with $3 \mathrm{~d}$ of recording: $r=\left(D /\left(D+S_{w}^{2} / S_{b}^{2}\right)\right)^{1 / 2}$

$\dagger$ Based on log-transformed data that do not fully follow a normal distribution.

$\ddagger$ Based on log-transformed data. 
dietary variables, the ability of the $3 \mathrm{~d}$ food records to assess intakes of fatty acids, cholesterol, vitamin A, folate, vitamin $\mathrm{E}$ and $\mathrm{B}_{12}$ in 3- and 6-year-old children could be criticised. The consequence of assessing all children by a $3 \mathrm{~d}$ food record in the DIPP study is that 1-year-old children with lower variation will have their intakes assessed with a higher accuracy, and, more importantly, 3- and 6-year-old children with higher variation will not have all nutrient intakes assessed with the degree of confidence required.

The present study differs from earlier surveys in that it includes the nutrient intake also from dietary supplements for the most common supplemental nutrients. Maximal insight into the relationship between nutrient intake and diseases requires examining the intake from both food and supplements. Among Finnish preschool children, this is of special importance when assessing the total intake of vitamin D. Vitamin D is known to have a number of immunological effects, and it may play a role in preventing several diseases ${ }^{(20)}$. Intake of vitamin D from supplements is of particular importance in countries located furthest north ${ }^{(21)}$, and vitamin D supplements are recommended for all Finnish children up to 3 years of age ${ }^{(22)}$. After the first year of age, the use of vitamin D supplements is increasingly influenced by sociodemographic factors ${ }^{(23,24)}$, and, accordingly, the use of supplements becomes more random. Consequently, the within-subject variation in subjects' intakes decreases compared with the variation between subjects, and fewer days of food record are needed for adequate intake estimates. Intake of nutrients other than vitamin D or fluoride from supplements is rare among preschool children ${ }^{(23)}$. The impact of supplemental intake of nutrients on variance estimates of preschoolers could, therefore, be considered to be rather low for nutrients other than vitamin D.

It is noteworthy that in all age groups, average variance ratios of macro- and micronutrients were greater in girls than in boys. This could imply sex differences in timing at introducing foods and adjusting to the family diet as shown in our earlier study ${ }^{(25)}$. There are conflicting findings on sex differences in previous reports ${ }^{(10,11,21)}$. The present study focused on separate age groups, whereas larger age ranges were used in earlier studies among children ${ }^{(4-6,9,10)}$. Despite differences in age range, some comparisons could be done. The nutrients with the highest variance ratios in relative terms were rather similar: cholesterol, fatty acids and vitamin $\mathrm{A}^{(5,10,11)}$. The estimates for macronutrients were quite close to ours, but the estimates for micronutrients were lower ${ }^{(4,5)}$. The differences might be due, at least partly, to differences in age range. As has been shown in previous studies, variance ratios were lower for toddlers and increased with age ${ }^{(5,9,10)}$.

The ultimate focus of nutritional epidemiology is on the association between diet and diseases. Measurement error due to an inadequate number of replicates and, therefore, attenuated linear regression estimates could reduce the strength of associations towards zero and mask real associations $^{(3)}$, resulting in false negatives. Bias attributable to within-subject variance can be partially removed during analysis, and several methods for applying statistical adjustment have been suggested ${ }^{(26)}$. However, their use in epidemiological studies of the diet-disease relationship has been limited. The present survey provided estimates of within- and between-subject variation of energy and nutrient intakes that can be used by other studies in preschool children. The application of within-subject variance estimates from other studies must be exercised with caution as variance components among children may vary by country ${ }^{(27)}$.

For many nutrients, obtaining a highly accurate estimate of individual intake by using required amount of repeated measurements is often beyond practical possibilities. Accordingly, a high number of repeated measurements could, in fact, cause more erroneous reporting (under-reporting) and increase the number of dropouts due to high respondent burden. Tooze $e t a l .{ }^{(28)}$ described the National Cancer Institute method that combines information from a short-term dietary assessment method (the $24 \mathrm{~h}$ recall) with that from another long-term report (the FFQ) to estimate distributions of foods' usual intakes in the general population. It was further demonstrated that the gain from combining two instruments may be substantial, with increases in the precision of the predicted usual intake and of the estimated diet-health outcome relationship ${ }^{(29)}$. In future research, the modelling of usual intake based on two or more repeated $24 \mathrm{~h}$ recalls (or food records) and the FFQ, using a method such as the National Cancer Institute method, is a notable alternative to increasing the number of repeated measurements.

Some limitations of the present study should be considered when interpreting the findings. We did not exclude potential under-reporters from the analysis. Ideally, we would have included anthropometric data, so that we would have had some data against which to check the reliability of food reporting. However, such data were not available at the time of the present study. All days of the week and all seasons were rather equally represented in the present study, and, therefore, the magnitude of these influences could be perceived as low. In a separate study among the present 3-year-old children, daily energy intake was similar on weekdays and weekends ${ }^{(30)}$. On weekdays, however, children had a higher intake of dietary fibre and protein and a lower intake of sucrose compared with weekends. Although the present cohort carries increased human leukocyte antigen-conferred susceptibility to type 1 diabetes, the subjects are expected to be representative of the general population of Finnish children. Almost $20 \%$ of the Finnish population carry increased human leukocyte antigen-conferred predisposition to type 1 diabetes, while only 3-4\% of those actually progress to clinical disease ${ }^{(31)}$. In terms of sociodemographic characteristics, the study samples were biased towards higher parental education and a smaller number of siblings. This may have had some bearing on the present results.

The present results imply that the ratio of within-subject variances to between-subject variances in preschool children increases with increasing age and is slightly greater in girls than in boys. In epidemiological studies, a sufficient number of replicates are required in order to detect diet-disease associations. In the light of the present results, three replicates are reasonable in 1-year-old children but must be questioned for several nutrients in 3- and 6-year-old children. The present 
estimations are particularly valuable when interpreting results of associations of nutrient intake and when designing future studies in children.

\section{Acknowledgements}

We express our gratitude to the children and parents who participated. We are grateful to the DIPP research nurses, doctors, nutritionists and all research fellows for excellent collaboration over the years. We thank Susan Wicht for language editing. The present study was supported by the Academy of Finland (grants 63672, 79685, 79686, 80846, 201988 and 210632); the Finnish Diabetes Association; the Finnish Diabetes Research Foundation; the Finnish Pediatric Research Foundation; the Häme Foundation of the Finnish Culture Fund; the Juho Vainio Foundation; the Yrjö Jahnsson Foundation; Medical Research Funds; Turku, Oulu and Tampere University Hospitals; JDRF (grants 197032, 4-1998-274, 4-1999-731 and 4-2001-435); Novo Nordisk Foundation; and EU Biomed 2 Program (BMH4-CT98-3314). The author's responsibilities were as follows: $\mathrm{M}$. E. participated in designing the study, preparing, analysing and interpreting the data, and wrote the manuscript; H.-M. T. participated in analysing and interpreting the data; P. K. and C. K.-K. participated in preparing and interpreting the data; J. N. participated in planning the statistical analyses and interpreting the data; R. V. participated in preparing the data; M. K., O. S. and J. I. participated in conceiving and designing the study; S. M. V. participated in designing the study and interpreting the data. All authors participated in drafting or revising the manuscript and approved the final version to be published. None of the authors had a personal or financial conflict of interest.

\section{References}

1. Greer FR, Sicherer SH \& Burks AW (2008) Effects of early nutritional interventions on the development of atopic disease in infants and children: the role of maternal dietary restriction, breastfeeding, timing of introduction of complementary foods, and hydrolyzed formulas. Pediatrics 121, 183-191.

2. Wu T \& Chen P (2009) Health consequences of nutrition in childhood and early infancy. Pediatr Neonatol 50, 135-142.

3. Willett W (1998) Nutritional Epidemiology, 2nd ed. New York: Oxford University Press.

4. Lanigan JA, Wells JCK, Lawson MS, et al. (2004) Number of days needed to assess energy and nutrient intake in infants and young children between 6 months and 2 years of age. Eur J Clin Nutr 58, 745-750.

5. Huybrechts I, De Bacquer D, Cox B, et al. (2008) Variation in energy and nutrient intakes among pre-school children: implications for study design. Eur $J$ Public Health 18, 509-516.

6. Black AE, Cole TJ, Wiles SJ, et al. (1983) Daily variation in food intake of infants from 2 to 18 months. Hum Nutr Appl Nutr 37, 448-458.

7. Paeratakul S, Popkin BM, Kohlmeier L, et al. (1998) Measurement error in dietary data: implications for the epidemiologic study of the diet-disease relationship. Eur J Clin Nutr $\mathbf{5 2}$, $722-727$.
8. Carriquiry AL (2003) Estimation of usual intake distributions of nutrients and foods. J Nutr 133, Suppl. 2, S601-S608.

9. Kylberg E (1986) Diets of healthy Swedish children 4-24 months old. IV. Daily variation of energy and nutrient intake. Hum Nutr Appl Nutr 40, 412-420.

10. Nelson M, Black AE, Morris JA, et al. (1989) Between- and within-subject variation in nutrient intake from infancy to old age: estimating the number of days required to rank dietary intakes with desired precision. Am J Clin Nutr 50, $155-167$.

11. Miller JZ, Kimes T, Hui S, et al. (1991) Nutrient intake variability in a pediatric population: implications for study design. J Nutr 121, 265-274.

12. Virtanen SM, Kenward MG, Erkkola M, et al. (2006) Age at introduction of new foods and advanced beta-cell autoimmunity in young children with HLA-conferred susceptibility to type 1 diabetes. Diabetologia 49, 1512-1521.

13. Kupila A, Muona P, Simell T, et al. (2001) Feasibility of genetic and immunological prediction of type I diabetes in a population-based birth cohort. Diabetologia 44, 290-297.

14. Paturi M, Nieminen R, Reinivuo H, et al. (2006) Ruokien annoskuvakirja (Food Portion Photo Book). Helsinki: Kansanterveyslaitos (in Finnish).

15. National Institute for Health and Welfare, Nutrition Unit (2005) Fineli. Finnish food composition database, release 5. http://www.fineli.fi

16. Kyttälä P, Erkkola M, Kronberg-Kippilä C, et al. (2010) Food consumption and nutrient intake in Finnish 1- to 6-year-old children. Public Health Nutr 13, Suppl. 6A, S947-S956.

17. Birch LL \& Fisher JO (1998) Development of eating behaviours among children and adolescents. Pediatrics 101, 539-549.

18. Nicklas TA, Webber LS \& Berenson GS (1991) Studies of consistency of dietary intake during the first four years of life in a prospective analysis: Bogalusa Heart Study. J Am Coll Nutr 10, 234-241.

19. Mikkilä V, Räsänen L, Raitakari OT, et al. (2005) Consistent dietary patterns identified from childhood to adulthood: the Cardiovascular Risk in Young Finns Study. Br J Nutr 93, 923-931.

20. Wang S (2009) Epidemiology of vitamin D in health and disease. Nutr Res Rev 22, 188-203.

21. Tylavsky FA, Cheng S, Lyytikäinen A, et al. (2006) Strategies to improve vitamin D status in northern European children: exploring the merits of vitamin $\mathrm{D}$ fortification and supplementation. J Nutr 136, 1130-1134.

22. Nordic Council of Ministers (2004) Nordic Nutrition Recommendations: Integrating Nutrition and Physical Activity, 4th ed. Copenhagen: Nordic Council of Ministers.

23. Marjamäki L, Räsänen M, Uusitalo L, et al. (2004) Use of vitamin D and other dietary supplements by Finnish children at the age of 2 and 3 years. Int J Vitam Nutr Res 74, 27-34.

24. Räsänen M, Kronberg-Kippilä C, Uusitalo U, et al. (2006) Intake of vitamin $\mathrm{D}$ by 3-month to 3-year-old children in Finland. Eur J Clin Nutr 96, 913-920.

25. Erkkola M, Pigg H-M, Virta-Autio P, et al. (2005) Infant feeding patterns in the Finnish type 1 diabetes prediction and prevention nutrition study cohort. Eur J Clin Nutr 59, $107-113$

26. Hoffmann K, Boeing H, Dufour A, et al. (2002) Estimating the distribution of usual dietary intake by short-term measurements. Eur J Clin Nutr 56, Suppl. 2, S53-S62.

27. Jahns L, Carriquiry A, Arab L, et al. (2004) Within- and between-person variation in nutrient intakes of Russian and U.S. children differs by sex and age. J Nutr $\mathbf{1 3 4}$, 3114-3120. 
28. Tooze JA, Midthune D, Dodd KW, et al. (2006) A new method for estimating the usual intake of episodicallyconsumed foods with application to their distribution. $J$ Am Diet Assoc 106, 1575-1587.

29. Kipnis V, Midthune D, Buckman DW, et al. (2009) Modeling data with excess zeros and measurement error: application to evaluating relationships between episodically consumed foods and health outcomes. Biometrics 65, 1003-1010.
30. Lehtisalo J, Erkkola M, Tapanainen H, et al. (2010) Food consumption and nutrient intake in day care and at home in 3-year-old Finnish children. Public Health Nutr 13, Suppl. 6A, S957-S964.

31. Ilonen J, Reijonen H, Herva E, et al. (1996) Rapid HLA-DQB1 genotyping for four alleles in the assessment of risk for IDDM in the Finnish population. The Childhood Diabetes in Finland (DiMe) Study Group. Diabetes Care 19, 795-800. 